Revista do CESP, Belo Horizonte, v.36, n.55, p. 97-104, 2016

\title{
Automatismo e indiferença em A Máquina de Joseph Walser, de Gonçalo M. Tavares
}

\section{Automatism and indifference in Joseph Walser's Machine by Gonçalo M. Tavares}

Rodrigo Medeiros Campos

Universidade Federal de Minas Gerais (UFMG), Belo Horizonte, Minas Gerais, Brasil rodrigocampos1977@gmail.com

Resumo: O objetivo deste artigo é provocar uma reflexão a respeito do automatismo e da indiferença presentes na sociedade atual a partir da leitura e da análise crítica da obra "A Máquina de Joseph Walser", de Gonçalo M. Tavares.

Palavras-chave: automatismo; indiferença; maquinismo; alienação.

Abstract: The aim of this article is to bring a reflection about the automatism and indifference present in the contemporarysociety, from the reading and critical analysis of the book "A Máquina de Joseph Walser", by Gonçalo M. Tavares.

Keywords: automatism; indifference; machinism; alienation.

Data de recebimento: 27 de junho de 2016

Data de aprovação: 30 de junho de 2016

O escritor português contemporâneo Gonçalo M. Tavares é um daqueles autores que transcendem o seu tempo. Liberto dos padrões definidores dos gêneros literários, Tavares transita livremente entre diferentes elementos narrativos, conferindo ao seu texto um estilo híbrido e próprio. Tão próprio que o autor adquiriu o hábito de segmentar 
suas obras em séries. Uma delas, denominada $O$ Reino, é composta, cronologicamente, pelos romances Um homem: Klaus Klump, A Máquina de Joseph Walser, Jerusalém e Aprender a rezar na era da técnica.

Embora os quatro romances apresentem autonomia e possam ser lidos de forma independente, os personagens que os compõem transitam entre estas obras, que também têm em comum os cenários de guerra (ou pós-guerra) e o fato de que as cidades não são identificáveis. Vamos nos ater, neste momento, ao segundo livro da tetralogia O Reino: A Máquina de Joseph Walser.

Lançado em 2004, o romance se passa em um cenário bélico, no qual as máquinas e a técnica se sobrepõem ao humano. A ideia de progresso e de continuidade a qualquer custo da produção (ou da simples atividade industrial, que não se traduz, necessariamente, em produtividade) é imposta sem que haja qualquer resistência dos personagens. As máquinas são, portanto, soberanas, provedoras da base econômica e ameaçadoras à integridade daqueles que as operam. Por isso, em dado momento, o narrador afirma que "_. As máquinas de guerra vêm aí, mas não tenha medo. $\mathrm{O}$ problema não são as máquinas que se aproximam da cidade, são as máquinas que já aqui estão". (TAVARES, 2004, p. 15). O "problema" aqui tem duplo sentido: ao mesmo tempo em que a máquina pode ferir, mutilar, matar fisicamente quem a opera, também ameaça a própria necessidade da existência humana. Assim, o risco de que a criatura se sobreponha ao criador (e o aniquile) está sempre presente na narrativa. As máquinas são, portanto, soberanas. É o ser humano quem serve as máquinas.

Este estado alienante e mecanicista que sugere, ao mesmo tempo, uma ligação física entre homem e máquina, conferindo organicidade ao metal e mecanicidade ao homem, remete-nos quase instintivamente à Ode Triunfal, de Álvaro de Campos, um dos heterônimos do também português Fernando Pessoa:

(...) Ó rodas, ó engrenagens, r-r-r-r-r-r-r eterno!

Forte espasmo retido dos maquinismos em fúria!

Em fúria fora e dentro de mim,

Por todos os meus nervos dissecados fora,

Por todas as papilas fora de tudo com que eu sinto!

Tenho os lábios secos, ó grandes ruídos modernos,

De vos ouvir demasiadamente de perto,

E arde-me a cabeça de vos querer cantar com um excesso 
De expressão de todas as minhas sensações,

Com um excesso contemporâneo de vós, ó máquina! (...)

(PESSOA, 2009, p. 37)

Paralelamente, em A Máquina de Joseph Walser, observamos, consternados, a relação entre o protagonista e o conjunto mecânico que o define como um operário fabril:

Joseph Walser sentia-se, de facto, observado por ela, pela "sua" máquina. Eram para ele claras as hierarquias das duas existências: a máquina era de uma hierarquia superior: poderia salvá-lo ou destruí-lo; poderia fazer a sua vida repetir-se, quase infinitamente, ou poderia, pelo contrário, de um momento para outro, provocar uma alteração súbita nos seus dias. Joseph Walser nunca percebia melhor o seu papel de empregado, a sua existência subserviente em relação ao exterior, do que em frente à máquina (...). (TAVARES, 2004, p. 21)

Esta superioridade da máquina sobre o homem, fortemente representada no campo simbólico, torna-se ainda mais evidente após o acidente no qual Joseph Walser perde um de seus dedos (o indicador da mão direita) ao manusear a sua máquina. A partir de então, Walser é realocado em uma atividade de escritório, pouco relevante em tempos de guerra, enquanto a máquina mantém o seu posto intocável, agora operada por outro funcionário.

Aspecto marcante de A Máquina de Joseph Walser é a sua condição temporal. Não se admite outro tempo que não seja o presente. E é aí que entramos em um paradoxo, já que a supervalorização das máquinas e da técnica está diretamente relacionada à exigência de um progresso permanente. Mas como pensar em progresso se o futuro é um conceito que, principalmente em períodos de conflitos armados, perde o sentido? A previsibilidade dos acontecimentos faz com que tenhamos uma sensação quase de "congelamento" temporal, como se, a partir de um mecanismo engenhosamente construído pelo homem, fôssemos capazes de fazer um recorte na história e nele viver (e morrer) sem sentir os efeitos do tempo. Essa "paralisação" cronológica (ou hipervalorização do presente) contribui para a perda da condição humanizadora do homem, já que tudo é programado, sabido, organizado, predefinido. Em dado momento, Tavares escreve: 
Veja esta fábrica: estamos perante o espanto sobrenatural. Tudo é tão estupidamente previsível nestas máquinas que se torna surpreendente; é o grande espanto do século, a grande surpresa: conseguimos fazer acontecer exatamente o que queremos que aconteça. Tornamos redundante o futuro, e aqui reside o perigo. Se a felicidade individual depende destes mecanismos e se torna também previsível, a existência será redundante e desnecessária: não haverá expectativas, luta ou pressentimentos. Fala-se em máquinas de guerra, mas nenhuma máquina é pacífica, Walser. (TAVARES, 2011, p. 151).

De forma semelhante, o passado é visto como sinônimo de inutilidade, desqualificação e imoralidade. Os sapatos usados por Joseph Walser são "velhos e gastos", portanto, imorais, causadores de uma deformação física e de caráter que se estende metaforicamente pelo homem que os calça. Walser, sempre preso à sua máquina, à técnica e ao presente, desumaniza-se a ponto de não mais se surpreender com fato algum: nem o adultério de Margha, sua mulher, com o encarregado Klober parece trazê-lo de volta à realidade. Ele prossegue, pois, em um estado de alienação e só encontra sentido no trabalho. Neste particular, Robert Musil nos ensina:

E como a posse de qualidades pressupõe uma certa alegria pela sua realidade, é legítimo prever que alguém a quem falte o sentido de realidade até em relação a si próprio passa um belo dia, sem saber como, a encarar-se como um homem sem qualidades. (MUSIL, 1989, p. 465)

Ao contrário de Klaus Klump, Joseph Walser não se envolve com a guerra. Mantendo-se à parte dos acontecimentos bélicos e políticos, Walser preserva a sua coleção de objetos metálicos com a minúcia de um profissional, como que para ordenar e devolver a si algum sentido. A coleção pode ser encarada como um espaço imaginário que marca, registra, confirma a passagem do indivíduo pelo mundo. A coleção de Walser é, pois, uma autorrepresentação e um desejo de estabelecer uma condição de ordem apartada de um contexto caótico de guerra. Como narra Tavares, "aquele mundo que, visto de fora, poderia parecer ilógico e estranho, estava profundamente ordenado; era uma segunda ordem, que só ele percebia". (TAVARES, 2011, p. 88). 
No jogo de dados, Walser também experimentava uma sensação falaciosa de controle e de poder, principalmente quando era ele, Walser, quem estava com os dados na mão, prestes a serem lançados sobre a mesa para assim determinar o futuro dos demais jogadores. Os dados serviam também como consolo, já que não exigiam escolhas, ao contrário da vida que as exige permanentemente:

Exigia-se, naquelas horas, um outro tipo de decisões, que não as que habitualmente os dias pediam a cada homem. Evaporava-se a tensão que resulta da existência de um número de possibilidades infinitas; ali, naquela mesa, cada um dos dados limitava os caminhos. E o que dava prazer a Joseph Walser era precisamente a sensação de que ali, finalmente, havia limites. Nada era desconhecido, não havia o algo mais que perturba, o algo mais não visível. (TAVARES, 2011, p. 162).

A incapacidade dos personagens de se indignarem (ou de se solidarizarem) com a dor alheia também chama a atenção. Ao perder um dos dedos da mão, Joseph não recebe os cuidados que se pode esperar em circunstâncias como essa. Nem Klober, o encarregado da fábrica, nem as enfermeiras e médicos do hospital, nem sua própria mulher, Margha, parecem se importar com a sua dor. A respeito da indiferença em relação à dor alheia na sociedade pós-moderna, João Barrento tece algumas considerações:

Não conhecemos a dor. (...) a dessolidarização constitutiva da sociedade de massas, mediatizada e globalizada, impede-nos de chegar a uma catarse coletiva, de ir além de um simulacro, de viver mais do que o espetáculo da dor. (...) A nossa incapacidade de um encontro catártico com a dor talvez tenha a ver com esta "incontinência verbal", que na verdade é uma perda da linguagem. Daquela dor $\mathrm{da} /$ na linguagem (a do inefável) que também se perdeu, tal como se perdeu, nesta nossa civilização narcísica do culto superficial da imagem, a capacidade de reconhecer o corpo vivo, e a sangrar, das palavras. (BARRENTO, 1999, p. 21-22).

Também não encontramos em A Máquina de Joseph Walser (e nem, tampouco, nos outros três romances que formam $O$ Reino) 
referências a uma relação transcendente do homem com qualquer conceito metafísico. As concepções de "divino" ou "espírito" são substituídas pelas ligações existentes entre homens e máquinas: "ser feliz já não depende de coisas que vulgarmente associamos à palavra Espírito. Depende de matérias concretas. A felicidade humana é um mecanismo" (TAVARES, 2010, p. 16).

A dependência de Joseph Walser à "sua" máquina não se limita ao campo econômico, portanto, mas alcança o aspecto existencial. $\mathrm{O}$ problema empiricamente levantado por Tavares se refere, pois, às implicações que a relação humana perante o mecanicismo provocam nas relações entre as pessoas e dessas com as concepções de tempo, desejo, autodeterminação. Neste sentido, as disputas de poder ganham um valor altamente figurado, uma vez que as máquinas mantêm movimentos repetitivos, previsíveis, isentos de preocupações éticas e das dinâmicas da frágil condição humana e o futuro se torna, assim, cíclico, uma autorreprodução (apesar das inovações técnicas e dos novos produtos) que apresenta uma ideia imperfeita de evolução da humanidade como espécie.

Totalmente rendidos, resignados e, principalmente, convencidos a respeito da soberania das máquinas sobre o ser humano, os personagens de A Máquina de Joseph Walser parecem viver num estado de torpor e indiferença a tudo o que ocorre ao seu redor (inclusive a guerra). O trabalho, ainda que seja um mero simulacro que não acarreta, necessariamente, um sistema eficazmente produtivo, torna-se o centro de uma vida desumanizadora. Eliane Brum faz um alerta em seu artigo publicado no jornal El País: ${ }^{1}$

Como na época da aceleração os anos já não começam nem terminam, apenas se emendam, tanto quanto os meses e como os dias, a metade de 2016 chegou quando parecia que ainda era março. Estamos exaustos e correndo. Exaustos e correndo. Exaustos e correndo. E a má notícia é que continuaremos exaustos e correndo, porque exaustose-correndo virou a condição humana dessa época. E já percebemos que essa condição humana um corpo humano não aguenta. O corpo então virou um atrapalho, um

\footnotetext{
${ }^{1}$ Disponível em: <http://brasil.elpais.com/brasil/2016/07/04/politica/1467642464_ 246482.html>. Acesso em: 14 jul. 2016.
} 
apêndice incômodo, um não-dá-conta que adoece, fica ansioso, deprime, entra em pânico. E assim dopamos esse corpo falho que se contorce ao ser submetido a uma velocidade não humana. Viramos exaustos-e-correndo-edopados. Porque só dopados para continuar exaustos-ecorrendo. Pelo menos até conseguirmos nos livrar desse corpo que se tornou uma barreira. O problema é que o corpo não é um outro, o corpo é o que chamamos de eu. O corpo não é limite, mas a própria condição. O corpo é.

Esta desumanização marcada por uma indolência, uma inércia crônica, traz o terrível risco da desistência do pensamento (e do verbo) e da banalização do mal. Neste sentido, Hanna Arendt, em "Algumas questões de filosofia moral", publicado em Responsabilidade e Juízo, nos instrui:

Da rejeição da escolha ou da incapacidade de escolhermos os nossos exemplos e a nossa companhia, da rejeição ou da incapacidade de entrarmos em relação com os outros através do juízo, emerge o verdadeiro skandala, os verdadeiros obstáculos que as forças humanas não conseguem demover, porque não têm por causa motivos humanos e humanamente inteligíveis. É aí que reside o horror, e ao mesmo tempo, a banalidade do mal. (ARENDT, 2004, p. 131)

Assim, por meio de A Máquina de Joseph Walser, Gonçalo M. Tavares nos alerta contra esta dormência coletiva: "Vê o mundo, o mundo tem uma lâmina" (TAVARES, 2011, p. 22).

$\mathrm{O}$ silêncio do indivíduo perante a dor alheia, bem como o alheamento social e político, dá margem, por fim, para que outros sons (mecânicos, violentos e amedrontadores) ganhem força no universo tavariano:

Não era um som orgânico. Nem orgânico bruto, nem orgânico inteligente, nem orgânico intelectualmente humano. Que sons, afinal, eram aqueles - o da bala, o do gatilho a ser preparado, o da granada? O de um certo som preto (...) repetir, exatamente o mesmo som com duas balas diferentes. (TAVARES, 2011, p. 104-105). 
É imprescindível, portanto, dar voz à palavra, ao verbo, para que a sociedade desperte desta letargia que fortalece o caos, a anomia e os abusos de poder.

\section{Referências}

ARENDT, Hannah. Algumas questões de filosofia moral. In: Responsabilidade e Juízo. Lisboa: Publicações Don Quixote: 1965.

BARRENTO, João. Dor é um fantasma do fim do século. Revista Românica, Lisboa, n. 8, p. 21-28, 1999.

BATAILLE, Georges. A Literatura e o Mal. Belo Horizonte: Autêntica, 2015.

MUSIL, Robert. O homem sem qualidades. Rio de Janeiro: Nova Fronteira, 1989.

PESSOA, Fernando. Ode Triunfal e outros poemas. São Paulo: Global, 2009.

TAVARES, Gonçalo M. A Máquina de Joseph Walser. São Paulo: Cia. das Letras, 2004. 